\title{
TLR4-dependent signaling pathway modulation: A novel mechanism by which pioglitazone protects against nutritional fibrotic steatohepatitis in mice
}

\author{
JINGHUA DU, XUEMIN NIU, RONGQI WANG, SUXIAN ZHAO, \\ LINGBO KONG, YUGUO ZHANG and YUEMIN NAN
}

Department of Traditional and Western Medical Hepatology, Third Hospital of Hebei Medical University, Shijiazhuang, Hebei 051000, P.R. China

Received February 26, 2015; Accepted December 14, 2015

DOI: $10.3892 / \mathrm{mmr} .2016 .4775$

\begin{abstract}
Activation of the innate immune system is involved in the development of chronic liver diseases, including nonalcoholic steatohepatitis. Toll-like receptor 4 (TLR4) is one of the sensors of the innate immune system. The aim of the present study was to elucidate the role of the TLR4-dependent signaling pathway, and examine the effect of pioglitazone on hepatic fibrosis, through modulation of the TLR4 pathway in a mouse model of nutritional fibrotic steatohepatitis. Male C57BL/6J mice were fed a methionine-choline deficient (MCD) diet for 8 weeks to induce nonalcoholic fibrotic steatohepatitis. The PPAR $\gamma$ agonist, pioglitazone, and PPAR $\gamma$ inhibitor, GW9662, were administered to the mice, respectively. The effects of the induction of PPAR $\gamma$ on liver biochemistry and histology, the modulation of TLR4 and its downstream pathway, and the expression levels of inflammatory and fibrogenic genes were
\end{abstract}

Correspondence to: Professor Yuemin Nan, Department of Traditional and Western Medical Hepatology, Third Hospital of Hebei Medical University, 139 Ziqiang Road, Shijiazhuang, Hebei 051000, P.R. China

E-mail: nanyuemin@163.com

Abbreviations: PPAR $\gamma$, peroxisome proliferator-associated receptor $\gamma$; TLR4, Toll-like receptor 4; MyD88, myeloid differentiation primary response gene 88 ; IKK- $\beta$, inhibitor of $\kappa \mathrm{B}$ kinase- $\beta$; NF- $\kappa \mathrm{B}$, nuclear factor $\kappa \mathrm{B}$; JNK1, c-Jun N-terminal protein kinase-1, AP-1, activator protein-1; TNF- $\alpha$, tumor-necrosis factor- $\alpha$; IL-1 $\beta$, interleukin-1 $\beta$; MCP-1, monocyte chemoattractant protein-1; MIP-1 $\alpha$, macrophage inflammatory protein-1 $\alpha$; Col-1, collagen type I; $\alpha$-SMA, $\alpha$-smooth muscle actin; TGF- $\beta 1$, transforming growth factor- $\beta 1$; BAMBI, basic membrane protein and activin membrane-bound inhibitor; GAPDH, glyceraldehydes 3-phosphate dehydrogenase

Key words: basic membrane protein and activin membrane-bound inhibitor, hepatic fibrosis, myeloid differentiation primary response gene 88 , nonalcoholic steatohepatitis, pioglitazone, Toll-like receptor 4 assessed using reverse transcription-quantitative polymerase chain reaction and Western blot analyses. The MCD-fed mice exhibited progressive hepatic steatosis, necrotic inflammation and fibrosis, along with increase levels of serum alanine aminotransferase and aspartate aminotransferase, accompanied by the upregulation of TLR4, the TLR4-myeloid differentiation primary response gene 88-dependent pathway and downstream genes, and proinflammatory and profibrotic genes; and downregulation of basic membrane protein and activin membrane-bound inhibitor. The administration of pioglitazone was found to reverse hepatic nutritional fibrosis via restoration of the expression levels of proinflammatory and profibrotic genes in the MCD-fed mice. The results of the present study provide novel evidence supporting the protective role of pioglitazone in ameliorating nutritional fibrotic steatohepatitis, through modulation of the TLR4-mediated signaling pathway.

\section{Introduction}

Nonalcoholic fatty liver disease (NAFLD) is one of the most common forms of chronic liver disease (1). Nonalcoholic steatohepatitis, which is intimately associated with the innate immune response, can be severe and lead to hepatic fibrosis and cirrhosis (2). Toll-like receptors (TLRs) are pattern recognition receptors, which are important in innate immunity. Increasing evidence has shown that TLRs are involved in the pathogenesis and progression of various liver diseases, including alcoholic liver disease, viral hepatitis and autoimmune liver disease (2-4). However, the mechanisms underlying the involvement of TLRs in NAFLD remain to be fully elucidated. Certain TLRs, particularly TLR4, are widely expressed on hepatic stellate cells (HSCs) and Kuppffer cells, and may be involved in liver fibrosis (5).

Peroxisome proliferator-associated receptor $\gamma(\operatorname{PPAR} \gamma)$ is a member of the nuclear receptor superfamily of transcription factors (6). Our previous investigations demonstrated that rosglitazone, a specific PPAR $\gamma$ agonist, has a protective role in the progression of nutritional fibrotic steatohepatitis, through the modulation of lipid homeostasis and the inflammatory response, and maintenance of HSC quiescence in mice (7-9). It has also 
been reported that pioglitazone, another specific PPAR $\gamma$ agonist, alleviates steatosis and steatohepatitis induced by consumption of a methionine-choline deficient (MCD) diet $(10,11)$.

In the present study, we aimed to clarify whether the TLR4-dependent signaling pathway is involved in the development of fibrotic steatohepatitis induced by an MCD diet, and to further elucidate whether pioglitazone can prevent liver injury by modulation of the TLR4 pathway and associated genes. The present study may provide an effective therapeutic target for the treatment of patients with nutritional fibrotic steatohepatitis.

\section{Materials and methods}

Animals and treatment. Male C57BL/6J mice (8-week-old; 20-25 g) were obtained from the Experimental Animals Center of the Chinese Academy of Medical Sciences (Beijing, China), and were bred in a temperature-controlled animal facility with a $12 \mathrm{~h}$ light-dark cycle. The mice had free access to water, and were fed with a standard rodent diet ad libitum for 1 week prior to the experiment to enable adaptation to the food and environment. The mice were randomly divided into four groups ( $\mathrm{n}=6$ per group): i) Control group, fed an MCD diet supplemented with choline bitartrate $(2 \mathrm{~g} / \mathrm{kg}$ ) and DL-methionine (3 $\mathrm{g} / \mathrm{kg}$; both ICN, Aurora, OH, USA); ii) MCD group, fed an MCD diet (ICN); iii) $\mathrm{MCD}+$ pioglitazone (PIO) group, fed an MCD diet with pioglitazone $(50 \mathrm{mg} / \mathrm{kg} / \mathrm{day}$; chow; GlaxoSmithKline Co., Ltd., Tianjin, China); iv) MCD+GW9662 group, fed an MCD diet and administered intraperitoneally with 2-chloro-5-nitrobenzani-liden (GW9662; $1 \mathrm{mg} / \mathrm{kg}$; three times per week; Alexis Biochemicals, Lausen, Switzerland). The duration of the experiment lasted up to 8 weeks. Following overnight fasting at the end of the experiments, all animals were sacrificed via exposure to $0.08 \mathrm{ml} / 1$ aether anesthesia (1.9\%), which was presented on a cotton ball inside a conical tube for 5-10 min. Blood samples were collected from the femoral arteries for biochemical analysis. The livers were weighed and either fixed in 10\% formalin for histological analysis, or snap-frozen in lipid nitrogen and stored at $-80^{\circ} \mathrm{C}$ until required. All protocols and procedures were performed in accordance with the the guidelines of the Hebei Committee for Care and Use of Laboratory Animals (Hebei, China) and were approved by the Animal Experimentation Ethics Committee of Hebei Medical University (Shijiazhuang, China).

Biochemical analysis. Prior to euthanasia, $0.5 \mathrm{ml}$ blood was harvested from each mouse via an orbital sinus puncture and the serum was separated by centrifugation at $1,500 \mathrm{x} g$ for $15 \mathrm{~min}$ at $4^{\circ} \mathrm{C}$. The levels of alanine aminotransferase (ALT) and aspartate aminotransferase (AST) were measured using an the enzymatic kinetic method with an automatic biochemical analyzer (UA2700; Olympus Corporation, Tokyo, Japan), according to the manufacturer's protocol.

Histological analysis. Liver tissues were cut into $5 \mu \mathrm{m}$-thick sections, paraffin-embedded and fixed for $16 \mathrm{~h}$ in $4 \%$ phosphate-buffered formalin at $4^{\circ} \mathrm{C}$ prior to hematoxylin and eosin and Masson's trichromatism staining. The liver sections were subsequently scored for hepatic steatosis, inflammation and fibrosis using a Leica DM 2000 microscope (Leica Microsystems, Inc., Buffalo Grove, IL), as described previously, in accordance with Brunt's criteria (12) and the histological scoring system for NAFLD issued by the Pathology Committee of the Nonalcoholic Steatohepatitis Clinical Research Network (13). The histological scoring system for NAFLD was as follows: Steatosis (0-3), lobular inflammation (0-2), hepatocellular ballooning (0-2), and fibrosis (0-4).

Reverse transcription-quantitative polymerase chain reaction (RT-qPCR) analysis of hepatic messenger RNA (mRNA) expression levels. Liver tissue samples were homogenized using $1 \mathrm{ml}$ TRIzol reagent (Invitrogen; Thermo Fisher Scientific, Inc.) per 50-100 mg tissue using a glass homogenizer. A total of $0.2 \mathrm{ml}$ chloroform was subsequently added per $1 \mathrm{ml}$ TRIzol reagent and the samples were vigorously vortexed for $15 \mathrm{sec}$ prior to incubation at room temperature for $2 \mathrm{~min}$. Following this, samples were centrifuged at $12,000 \mathrm{x}$ g for $15 \mathrm{~min}$ at $4^{\circ} \mathrm{C}$. The aqueous phase of the sample was transferred to a new tube and supplemented $0.5 \mathrm{ml} 100 \%$ isopropanol prior to incubation at room temperature for $10 \mathrm{~min}$ and centrifugation at $12,000 \mathrm{x} \mathrm{g}$ for $10 \mathrm{~min}$ at $4^{\circ} \mathrm{C}$. Total RNA was isolated from the frozen liver tissues using TRIzol reagent (Invitrogen; Thermo Fisher Scientific, Inc., Waltham, MA, USA), according to the manufacturer's protocol. Subsequently, $1 \mu \mathrm{g}$ total RNA was reverse transcribed into cDNA using a cDNA synthesis kit (Thermo Fisher Scientific Inc.), according to the manufacturer's instructions The hepatic mRNA levels of PPAR $\gamma$, TLR4, myeloid differentiation primary response gene 88 (MyD88), inhibitor of $\kappa \mathrm{B}$ kinase- $\beta$ (IKK- $\beta$ ), nuclear factor- $\kappa \mathrm{B}$ $(\mathrm{NF}-\kappa \mathrm{B})$; c-Jun N-terminal protein kinase 1 (JNK1), activator protein-1 (AP-1), bone morphogenetic protein and activin membrane-bound inhibitor (BAMBI), transforming growth factor- $\beta 1$ (TGF- $\beta 1), \alpha$-smooth muscle actin ( $\alpha$-SMA), collagen type I (Col-1), tumor-necrosis factor- $\alpha$ (TNF- $\alpha)$, interleukin-1 $\beta$ (IL-1 $\beta$ ), monocyte chemoattractant protein-1 (MCP-1), macrophage inflammatory protein-1 $\alpha$ (MIP-1 $\alpha)$, were determined by RT-qPCR using an ABI PRISM 7500 sequence detection system (Applied Biosystems; Thermo Fisher Scientific, Inc.). RT-qPCR was performed at a final reaction volume of $50 \mu \mathrm{l}$ containing $2 \mu \mathrm{l}$ cDNA, 5 pmol specific primers, $25 \mu \mathrm{l} \mathrm{SYBR}$ Green reagent (CWBio, Beijing, China) and $23 \mu \mathrm{l}$ water. Thermal cycling was completed as follows: $95^{\circ} \mathrm{C}$ for $5 \mathrm{~min}$, followed by 20 cycles of $95^{\circ} \mathrm{C}$ for $30 \mathrm{sec}$ and $60^{\circ} \mathrm{C}$ for $30 \mathrm{sec}$. Expression levels of the target genes were normalized against an endogenous reference gene, glyceraldehydes 3-phosphate dehydrogenase (GAPDH), and were calculated using the $2^{-\Delta \Delta C q}$ method (14) using ABI PRISM 7500 Sequence Detection software. The specific primers for PPAR $\gamma$, TLR4, MyD88, IKK- $\beta$, NF- $\kappa$ B, JNK1, AP-1, TNF- $\alpha$, IL-1 $\beta$, MCP-1, MIP-1 $\alpha$, BAMBI, TGF- $\beta 1, \alpha$-SMA, Col-1 and GAPDH were designed using Primer Premier 5.0 (Premier Biosoft, Palo Alto, CA, USA), and the sequences are listed in Table I. All data were obtained using Sequence Detector software.

Western blot analysis of hepatic protein expression levels. Total hepatic proteins were extracted using radioimmunoprecipitation assay lysis buffer (Thermo Fisher Scientific, Inc.), and the protein concentration was measured using the Bradford method 
Table I. Primers used for reverse transcription-quantitative polymerase chain reaction analysis.

\begin{tabular}{|c|c|c|}
\hline Gene & $\begin{array}{c}\text { Product } \\
\text { length (bp) }\end{array}$ & Primer sequence \\
\hline $\operatorname{PPAR} \gamma$ & 150 & $\begin{array}{l}\text { F: 5'-CACTCGCATTCCTTTGACATC-3' } \\
\text { R: 5'-CGCACTTTGGTATTCTTGGAG-3' }\end{array}$ \\
\hline TLR4 & 166 & $\begin{array}{l}\text { F: 5'-GAGCCGTTGGTGTATCTTTGA-3' } \\
\text { R: 5'-CTCCCATTCCAGGTAGGTATT-3' }\end{array}$ \\
\hline MyD88 & 150 & $\begin{array}{l}\text { F: 5'-CACTCGCATTCCTTTGACATC-3' } \\
\text { R: 5'-CGCACTTTGGTATTCTTGGAG-3' }\end{array}$ \\
\hline IKK- $\beta$ & 308 & $\begin{array}{l}\text { F: 5'-GGACTTCTTCAAAACCAGCATC-3' } \\
\text { R: 5'-CACCTTCTGTCCTTTGGTCTCT-3' }\end{array}$ \\
\hline $\mathrm{NF}-\kappa \mathrm{B}$ & 98 & $\begin{array}{l}\text { F: 5'-GTAGAGGATTTGCTGAGGGTG-3' } \\
\text { R: 5'-ATTCTGTCGTGTCCTTCTTTGG-3' }\end{array}$ \\
\hline JNK-1 & 166 & $\begin{array}{l}\text { F: 5'-TCAAGCACCTTCACTCTG-3' } \\
\text { R: 5'-CAAACCATTTCTCCCATA-3' }\end{array}$ \\
\hline AP-1 & 308 & $\begin{array}{l}\text { F: 5'-CGGACCGTTCTATGACTGC-3' } \\
\text { R: 5'-AGCGTGTTCTGGCTATGC-3' }\end{array}$ \\
\hline TNF- $\alpha$ & 98 & $\begin{array}{l}\text { F: 5'-CTGTGAAGGGAATGGGTGTT-3' } \\
\text { R: 5'-CAGGGAAGAATCTGGAAAGGTC-3' }\end{array}$ \\
\hline IL-1 $\beta$ & 233 & $\begin{array}{l}\text { F: 5'-AGGCTCCGAGATGAACAA-3' } \\
\text { R: 5'-AAGGCATTAGAAACAGTCC-3' }\end{array}$ \\
\hline MCP-1 & 150 & $\begin{array}{l}\text { F: 5'-TTCCACGCTCTTATCCTA-3' } \\
\text { R: 5'-CATCTCGTTGCTACCTCC-3' }\end{array}$ \\
\hline MIP-1 $\alpha$ & 166 & $\begin{array}{l}\text { F: 5'-CTGCCCTTGCTGTTCTTC-3' } \\
\text { R: 5'-GTTCCAGGTCAGTGATGTA-3' }\end{array}$ \\
\hline Col-1 & 308 & $\begin{array}{l}\text { F: 5'-GGGCGAGTGCTGTGCCTTT-3' } \\
\text { R: 5'-GAGCCATTGGACCTGAACC-3' }\end{array}$ \\
\hline$\alpha-\mathrm{SMA}$ & 98 & $\begin{array}{l}\text { F: 5'-CTGACAGAGGCACCACTGAA-3' } \\
\text { R: 5'-CATCTCCAGAGTCCAGCACA-3' }\end{array}$ \\
\hline TGF- $\beta 1$ & 233 & $\begin{array}{l}\text { F: 5'-GGCGGTGCTCGCTTTGTA-3' } \\
\text { R: 5'-AGCCACTCAGGCGTATCAG-3' }\end{array}$ \\
\hline BAMBI & 308 & $\begin{array}{l}\text { F: 5'-AGTGACTAGCAGGGAAAT-3' } \\
\text { R: 5'-AAGGAGCAGATAGAGGAG-3' }\end{array}$ \\
\hline GAPDH & 233 & $\begin{array}{l}\text { F: 5'-GGTGAAGGTCGGTGTGAACG-3' } \\
\text { R: 5'-CTCGCTCCTGGAAGATGGTG-3' }\end{array}$ \\
\hline
\end{tabular}

PPAR $\gamma$, peroxisome proliferator-associated receptor $\gamma$; TLR4, Toll-like receptor 4; MyD88, myeloid differentiation primary response gene 88; IKK- $\beta$, inhibitor of $\kappa \mathrm{B}$ kinase- $\beta$; NF- $\kappa \mathrm{B}$, nuclear factor $\kappa \mathrm{B}$; JNK1, c-Jun N-terminal protein kinase-1, AP-1, activator protein-1; TNF- $\alpha$, tumor-necrosis factor- $\alpha$; IL-1 $\beta$, interleukin-1 $\beta$; MCP-1, monocyte chemoattractant protein-1; MIP-1 $\alpha$, macrophage inflammatory protein-1 $\alpha$; Col-1, collagen type I; $\alpha$-SMA, $\alpha$-smooth muscle actin; TGF- $\beta 1$, transforming growth factor- $\beta 1$; BAMBI, basic membrane protein and activin membrane-bound inhibitor; GAPDH, glyceraldehydes 3-phosphate dehydrogenase; F, forward; R, reverse.

(DC protein assay; Bio-Rad Laboratories, Inc., Hercules, CA, USA). Loading buffer (Beijing Solarbio Science \& Technology Co., Ltd., Beijing, China) was added to each lysate, which contained equal quantities of protein (100 $\mu \mathrm{g} / \mathrm{well})$. The lysate was boiled for $5 \mathrm{~min}$ and then electrophoresed on $10 \%$ SDS-polyacrylamide gels. The proteins were then transferred onto equilibrated polyvinylidene difluoride membranes (EMD Millipore, Billerica, MA, USA) by electroblotting. The membranes were incubated, respectively, with the following primary antibodies overnight at $4^{\circ} \mathrm{C}$ : Mouse polyclonal anti-PPAR $\gamma$ (1:400; sc-122729; Santa Cruz Biotechnology, Inc., Santa Cruz, CA, USA); rabbit polyclonal anti-TLR4 (1:1,000; ab13556; Abcam, Cambridge, MA, USA); rabbit monoclonal anti-MyD88 (1:,1000; 4283; Cell Signaling Technology, Inc., Danvers, MA, USA); rabbit polyclonal anti-IKK- $\beta$ (ab55404; Abcam); and mouse monoclonal anti-NF-кB (1:400; sc-8414; Santa Cruz Biotechnology, Inc.). And the following rabbit polyclonal primary antibodies against: JNK1 (bs-10562R); 

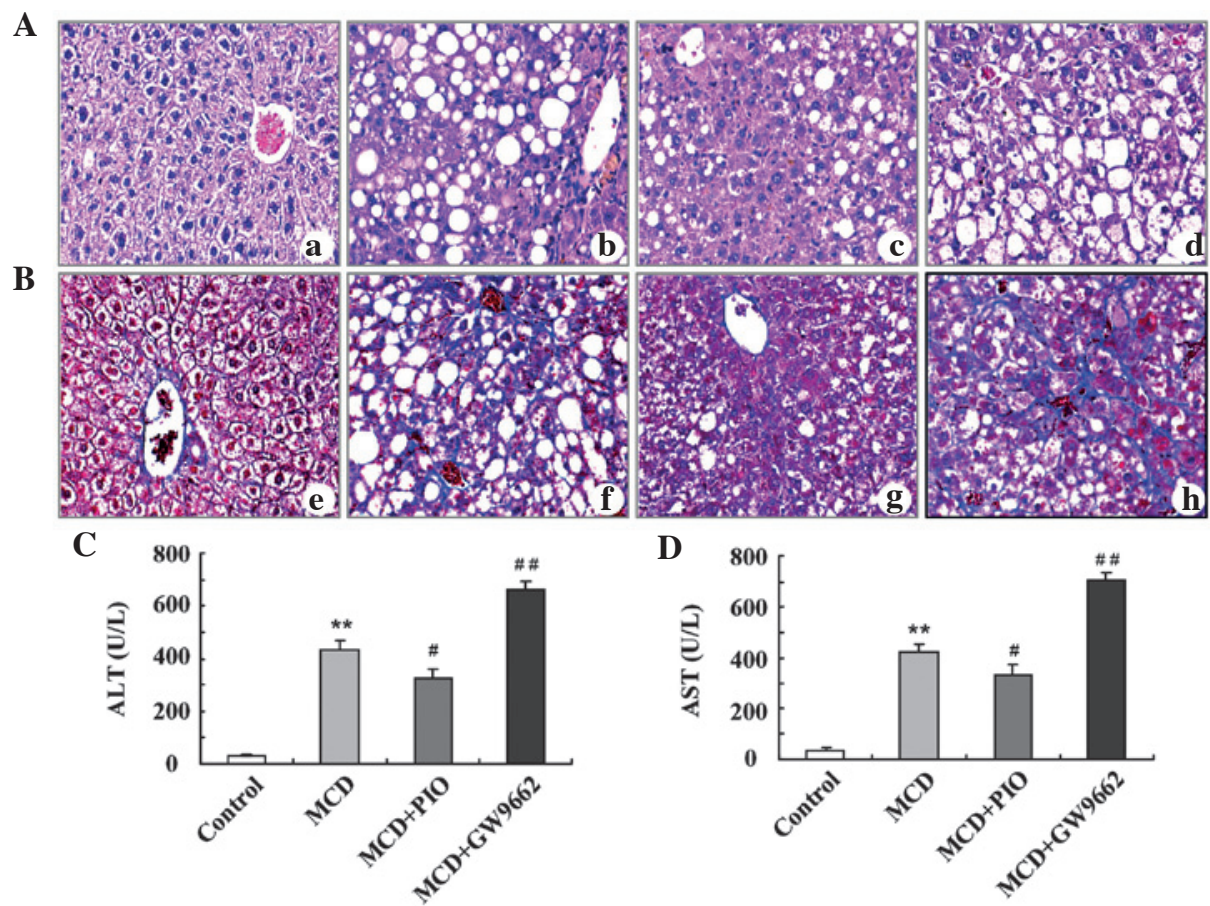

Figure 1. Histopathological changes and serum levels of ALT and AST of mice under various treatment conditions. (A) Hematoxylin and eosin-stained and (B) Masson's trichome-stained liver sections from the mice (Original magnification, x200), (a) Control, (b) MCD, (c) MCD+PIO, (d) MCD+GW9662; (C) Serum levels of ALT; (D) serum levels of AST ( $\mathrm{n}=6$ per group). Data are expressed as the mean \pm standard deviation. * $\mathrm{P}<0.01$, compared with the Control group; ${ }^{\#} \mathrm{P}<0.05$, compared with the MCD group; ${ }^{\# /} \mathrm{P}<0.01$, compared with the MCD group. ALT, alanine aminotransferase; AST, aspartate aminotransferase; MCD, methionine-choline deficient; PIO, pioglitazone.

AP-1 (bs-0670R); TNF- $\alpha$ (bs-2081R); IL-1 $\beta$ (bs-0812R); MCP-1 (bs-0562R); MIP-1 $\alpha$ (bs-1045R); BAMBI (bs-12418R); TGF- $\beta 1$ (bs-0086R); $\alpha$-SMA (bs-0819R); Col-1 (bs-7158R); and $\beta$-actin (bs-0061R; all 1:400; all Biosynthesis Biotechnology, Co., Ltd., Beijing, China). The membranes were then incubated with appropriate peroxidase-conjugated secondary antibodies at room temperature for $1 \mathrm{~h}$. Bands were visualized using enhanced chemiluminescence (GE Healthcare Bio-Sciences, Pittsburgh, PA, USA), followed by exposure to an X-ray film (Kodak, Rochester, NY, USA). The protein expression levels were normalized to that of $\beta$-actin in the same sample, and the expression levels were quantified by scanning densitometry using Quantity One V4.62 software (Bio-Rad Laboratories, Inc.).

Statistical analysis. All data are expressed as the mean \pm standard deviation. Statistical analyses of the data were performed using one-way analysis of variance (15) or a Kruskal-Wallis $H$-test, with a least significant difference t-test or Mann-Whitney U test for post-hoc comparison using SPSS 17.0 (SPSS Inc., Chicago, IL, USA). P $<0.05$ was considered to indicate a statistically significant difference.

\section{Results}

Pioglitazone activates PPAR $\gamma$, and ameliorates hepatic inflammation and fibrosis in mice fed an MCD diet. The MCD diet induced steatohepatitis and liver fibrosis in the mice, as shown in Fig. 1, which was in accordance with the effects observed in our previous study (16). Compared with the control group, the MCD group showed disordered lobule structure, macrosteatosis in Zone 3, spot or focal hepatocyte necrosis, inflammatory infiltration (Fig. 1A), and portal and persinusoidal fibrosis (Fig. 1B) in the liver sections, which were accompanied with significantly downregulated mRNA and protein expression levels of hepatic PPAR $\gamma$, which were decreased further by GW9662 administration $(\mathrm{P}<0.01)$. Pioglitazone administration markedly ameliorated hepatic steatosis, inflammation (Fig. 1A) and progressive fibrosis (Fig. 1B), which were associated with marked decreases in serum ALT (1) and AST (Fig. 1C and D; P<0.01). However, the opposite effect was observed in the MCD+GW9662 group, which exhibited aggravated steatosis, inflammation and fibrosis (Fig. 1A and B), and further increase in the serum aminotransferase levels (Fig. 1C and D).

Pioglitazone downregulates the hepatic expression levels of TLR4 and MyD88. The hepatic expression levels of TLR4 and MyD88 were significantly higher in the MCD-fed mice, compared with those in the control mice $(\mathrm{P}<0.01)$. Pioglitazone administration significantly upregulated the mRNA expression of PPAR $\gamma$ (Fig. 2). Following the induction of PPAR $\gamma$ by pioglitazone, the mRNA expression levels of TLR4 and MyD88 were downregulated, compared with those in the MCD group. However, the administration of GW9662 led to further upregulation in the mRNA levels of TLR4 and MyD88 (Fig. 2B and $\mathrm{C} ; \mathrm{P}<0.01$ ). The same results were observed on examination of the protein expression levels of PPAR $\gamma$ (Fig. 2D), TLR4 (Fig. 2E) and MyD88 (Fig. 2F).

Pioglitazone suppresses hepatic gene expression levels downstream of TLR4. To further investigate the TLR4-mediated 


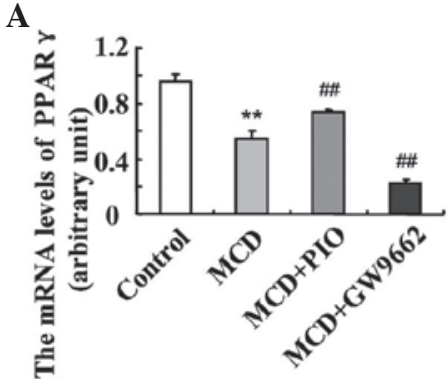

D

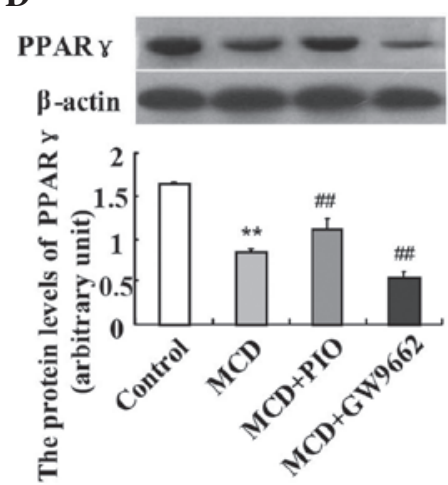

B

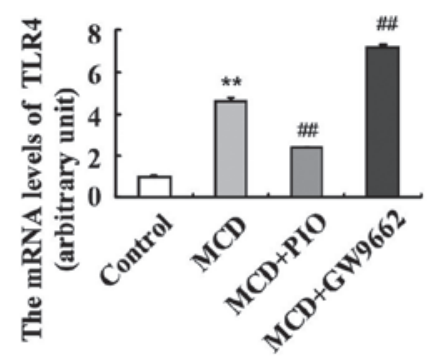

$\mathbf{E}$

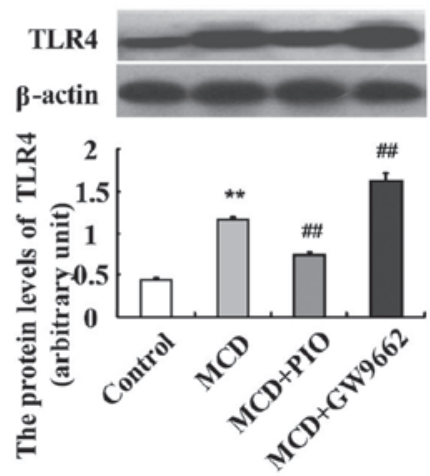

C

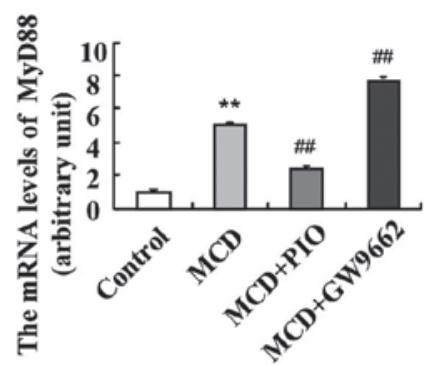

$\mathbf{F}$

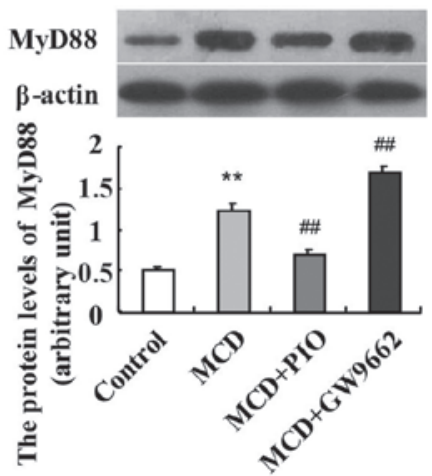

Figure 2. Effect of pioglitazone on the hepatic expression levels of PPAR $\gamma$, TLR4 and MyD88 in nutritional fibrotic steatohepatitis. The mRNA expression levels of (A) PPAR $\gamma$, (B) TLR4 and (C) MyD88 were examined using reverse transcription-quantitative polymerase chain reaction abakysis. The protein expression levels of (D) PPAR $\gamma$, (E) TLR4 and (F) MyD88 were measured by Western blot. $n=6$ per group. Data are expressed as mean \pm standard deviation. ${ }^{* *} \mathrm{P}<0.01$ compared with Control group; ${ }^{\# \#} \mathrm{P}<0.01$ compared with MCD group. MCD, methionine-choline deficient; PIO, pioglitazone; PPAR $\gamma$, peroxisome proliferator-associated receptor $\gamma$; TLR4, Toll-like receptor 4; MyD88, myeloid differentiation primary response gene 88.

A

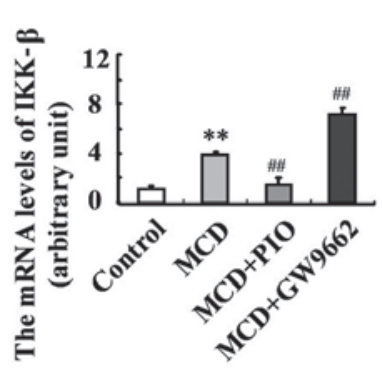

$\mathbf{E}$

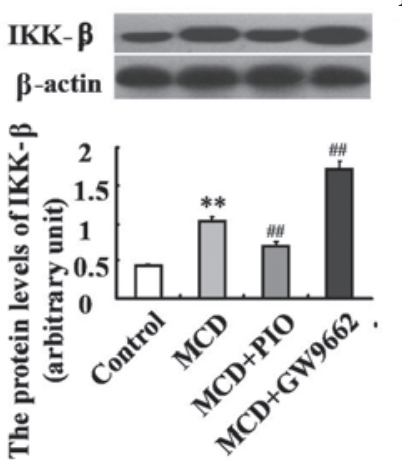

B

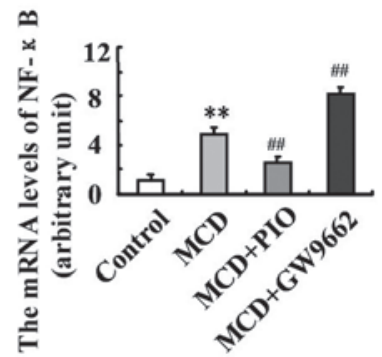

$\mathbf{F}$

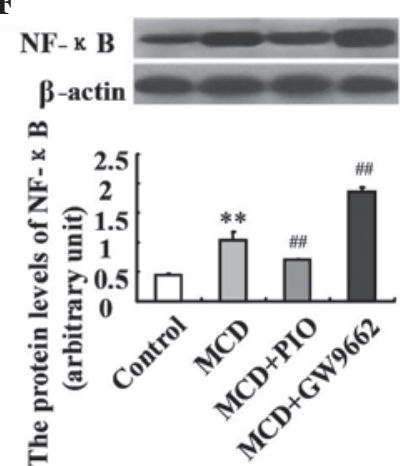

C

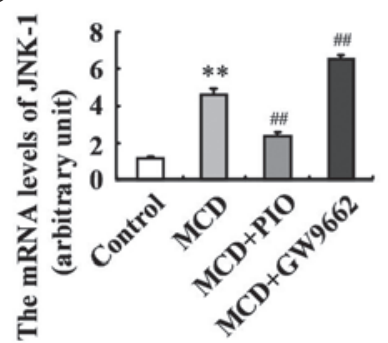

G
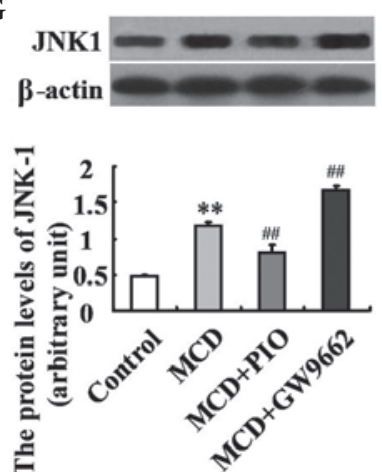

D

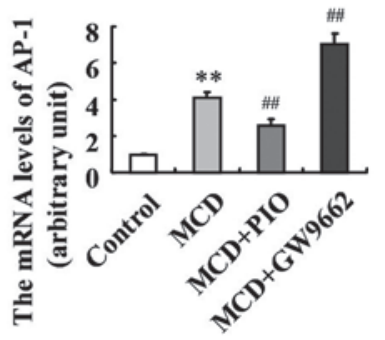

$\mathbf{H}$
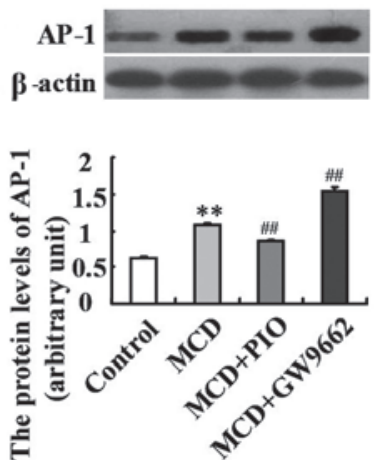

Figure 3. Effect of pioglitazone on the expression levels of IKK- $\beta$, NF- - B, JNK1 and AP-1 in nutritional fibrotic steatohepatitis-induced mice. The mRNA expression levels of (A) IKK- $\beta$, (B) NF- KB, (C) JNK1 and (D) AP-1 were examined using reverse transcription-quantitative polymerase chain reactionanalysis. The protein expression levels of (E) IKK- $\beta,(\mathrm{F}) \mathrm{NF}-\mathrm{\kappa B},(\mathrm{G}) \mathrm{JNK} 1$ and (H) AP-1 were measured using Western blotting. $\mathrm{n}=6$ per group. Data are expressed as the mean \pm standard deviation. ${ }^{* *} \mathrm{P}<0.01$, compared with the Control group; ${ }^{\# \#} \mathrm{P}<0.01$, compared with the MCD group. MCD, methionine-choline deficient; PIO, pioglitazone; IKK- $\beta$, inhibitor of $\kappa \mathrm{B}$ kinase- $\beta$; NF- $\mathrm{B}$, nuclear factor $\kappa \mathrm{B}$; JNK1, c-Jun N-terminal protein kinase-1, AP-1, activator protein-1.

inflammatory response and determine the anti-inflammatory effects of pioglitazone, the present study investigated hepatic mRNA and protein expression levels of the MyD88-dependent signaling pathway and downstream genes, IKK- $\beta, N F-\kappa B$, JNK1 and AP-1. Compared with the controls, the hepatic mRNA and protein expression levels of IKK- $\beta$, NF- $\kappa$ B, JNK1 
A

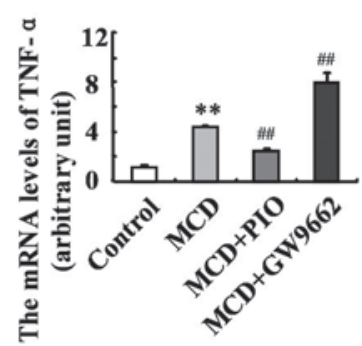

E
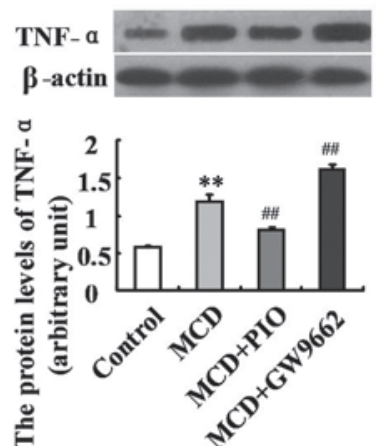

B
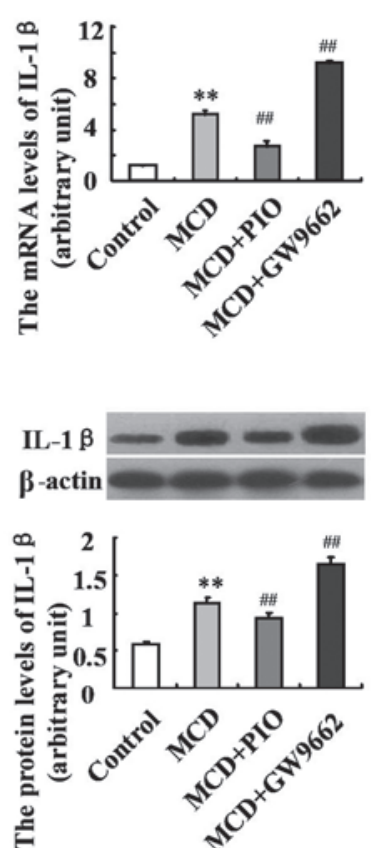

C

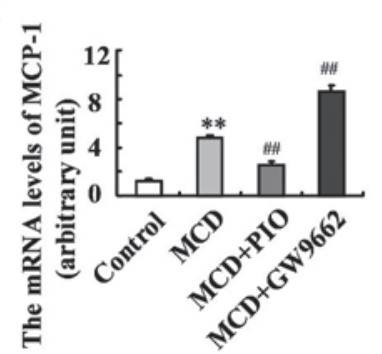

G

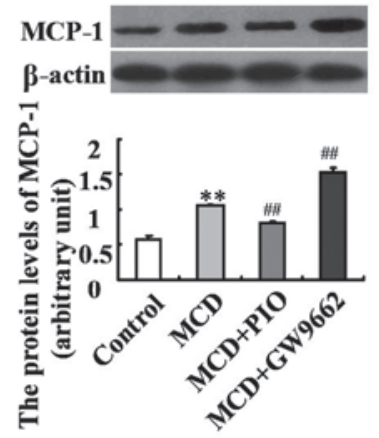

D

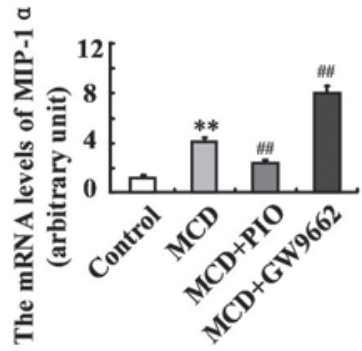

Figure 4. Effect of pioglitazone on the expression of inflammatory cytokines and chemokines in mice. The mRNA expression levels of (A) TNF- $\alpha$, (B) IL-1 $\beta$, (C) MCP-1 and (D) MIP-1 $\alpha$ were examined using reverse transcription- quantitative polymerase chain reaction analysis. Protein expression levels of (E) TNF-, (F) IL-1 $\beta,(\mathrm{G}) \mathrm{MCP}-1$ and $(\mathrm{H}) \mathrm{MIP}-1 \alpha$ were measured using Western blotting. $\mathrm{n}=6$ per group. Data are expressed as mean \pm standard deviation. ${ }^{* *} \mathrm{P}<0.01$, compared with the Control group; ${ }^{\# \#} \mathrm{P}<0.01$, compared with the MCD group. MCD, methionine-choline deficient; PIO, pioglitazone; TNF- $\alpha$, tumor-necrosis factor- $\alpha$; IL-1 $\beta$, interleukin-1 $\beta$; MCP-1, monocyte chemoattractant protein-1; MIP-1 $\alpha$, macrophage inflammatory protein-1 $\alpha$.
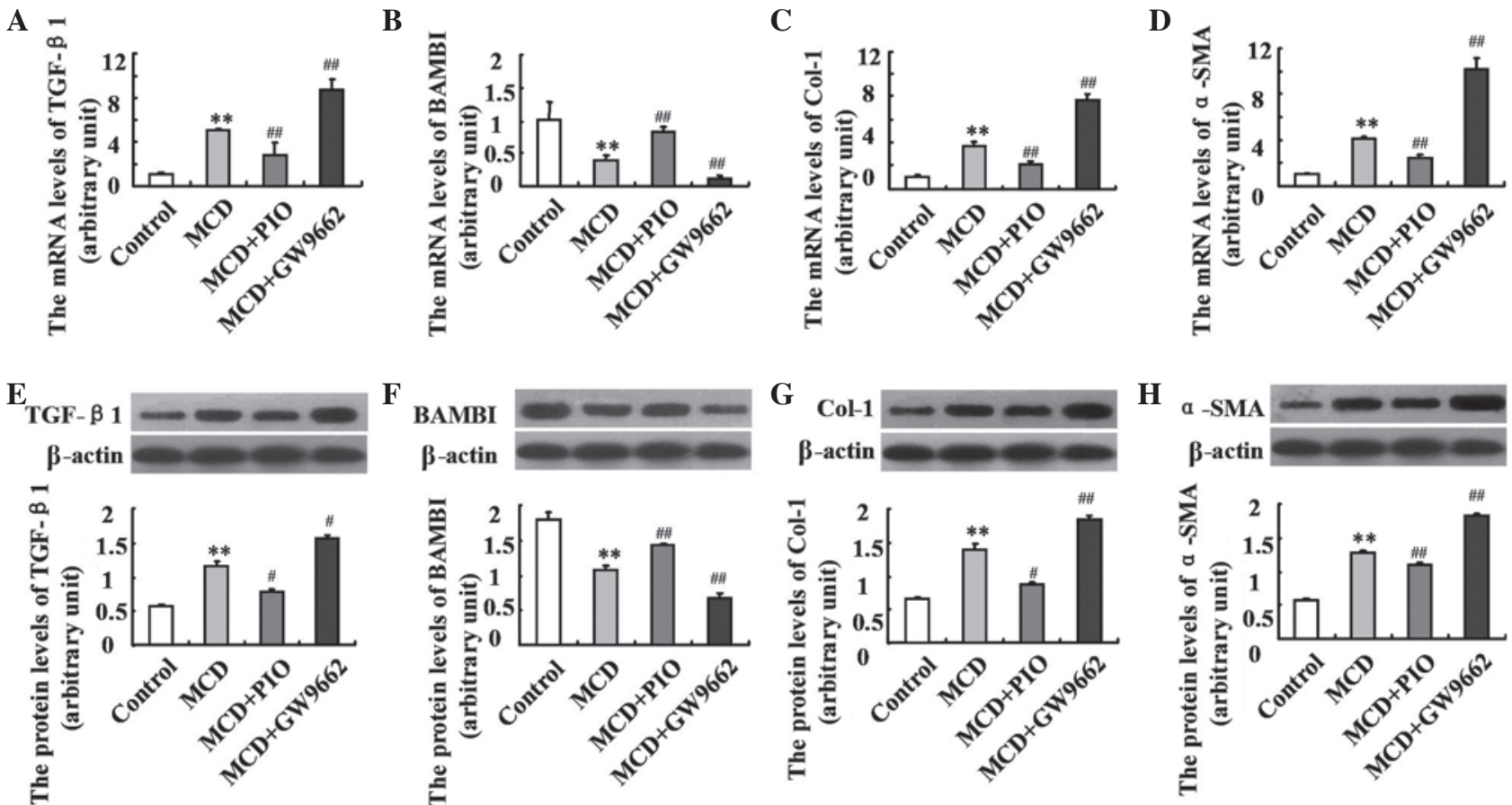

Figure 5. Effect of pioglitazone on the expression levels of fibrosis-associated genes in nutritional fibrotic steatohepatitis-induced mice. The mRNA expression levels of (A) TGF- $\beta 1$, (B) BAMBI, (C) Col-1 and (D) $\alpha$-SMA were examined using reverse transcription quantitative polymerase chain reaction analysis. The protein expression levels of (E) TGF- $\beta 1$, (F) BAMBI, (G) Col-1 and (H) $\alpha$-SMA were measured using Western blotting. $\mathrm{n}=6$ per group. Data are expressed as the mean \pm standard deviation. ${ }^{*} \mathrm{P}<0.05$ and ${ }^{* *} \mathrm{P}<0.01$, compared with the Control group; ${ }^{*} \mathrm{P}<0.05$ and ${ }^{\# \#} \mathrm{P}<0.01$, compared with the MCD group. MCD, methionine-choline deficient; PIO, pioglitazone; Col-1, collagen type I; $\alpha$-SMA, $\alpha$-smooth muscle actin; TGF- $\beta 1$, transforming growth factor- $\beta 1$; BAMBI, basic membrane protein and activin membrane-bound inhibitor.

and AP-1 were markedly increased in the MCD-fed mice $(\mathrm{P}<0.01)$, and these levels were significantly reduced by pioglitazone $(\mathrm{P}<0.01)$, as shown in Fig. 3. By contrast, the hepatic
mRNA and protein expression levels of IKK- $\beta$, NF- $\kappa \mathrm{B}$, JNK1 and AP-1 were further upregulated by GW9662 treatment, compared with the MCD group (Fig. 3; $\mathrm{P}<0.01$ ). 
Pioglitazone downregulates hepatic expression levels of proinflammatory cytokines and chemokines. To further examine the mechanism underlying PPAR $\gamma$-induced amelioration of liver histology, the present study examined the hepatic expression levels of inflammatory cytokines and chemokines. Compared with the control group, the hepatic expression levels of TNF- $\alpha$, IL-1 $\beta$, MCP-1 and MIP- $1 \alpha$ were upregulated in the MCD diet-fed mice $(\mathrm{P}<0.01 ;$ Fig. 4). These induced expression levels were significantly decreased by pioglitazone treatment. Treatment with GW9662 led to further increases in the expression levels of TNF- $\alpha$, IL-1 $\beta$, MCP- 1 and MIP- $1 \alpha$, compared with the levels in the mice fed an MCD diet (Fig. 4; $\mathrm{P}<0.01$ ).

Pioglitazone modulates the expression levels of fibrosis-associated genes. To evaluate the effect and mechanisms of PPAR $\gamma$-induced fibrotic steatohepatitis, the present study assessed the hepatic expression levels of fibrosis-associated genes. The mice fed an MCD diet showed enhanced hepatic mRNA and protein expression levels of TGF- $\beta 1, \alpha-S M A$ and Col-1 $(\mathrm{P}<0.01)$, which were depressed by pioglitazone administration. By contrast, the mRNA and protein expression levels of BAMBI were significantly lower in the MCD-fed mice, compared with the control mice, and were markedly increased following treatment of pioglitazone (both $\mathrm{P}<0.01$ ). The opposite changes were observed in the GW9662 group, compared with the MCD group (Fig. 5; P<0.01).

\section{Discussion}

Nutritional fibrotic steatohepatitis is a complex multifactorial disease, and is associated with abnormal lipid metabolism, oxidative stress, inflammation and the immune response (17). Investigations have focussed on the potential mechanisms responsible for the effect of PPAR $\gamma(18-20)$. The results of the present study showed that the hepatic expression of PPAR $\gamma$ was significantly lower in the MCD-fed mice, compared with the control mice, which was consistent with indicators of liver injury, including increased levels of serum ALT and AST, hepatic steatosis, necrotic inflammation and fibrosis. The present study further demonstrated that the induction of PPAR $\gamma$ by administration of the specific agonist, pioglitazone, for 8 weeks markedly attenuated liver injury, as evidenced by decreased levels of serum ALT and AST, a reduced inflammatory response, reduced collagen deposition and suppressed HSC activation. These results indicated that PPAR $\gamma$ modulation had an important protective role in the progression of NALFD

A novel finding in the present study was that TLR4 was closely involved in the development of liver fibrosis, and the inhibitory effects of pioglitazone on the inflammatory response and fibrogenesis in fibrotic steatohepatitis. With the progression of liver fibrosis in the present study, the hepatic expression of TLR4 increased, suggesting that TLR4 may be involved in the development of MCD-diet induced liver injury. The downstream proinflammatory cytokines, MyD88, IKK- $\beta$, NF- $\kappa \mathrm{B}$, JNK1 and AP-1, remained consistent with the change in TLR4 in the mice. The results of the present study were supported by evidence in a previous study, that the expression levels of TLR4 and MyD88, the adaptor protein for TLR4, are significantly increased in fructose or L-amino-acid-defined diet-induced
NAFLD (21-23). Furthermore, the interaction between TLR4 and MyD88 triggered a downstream signaling cascade, which led to activation of the IKK- $\beta / \mathrm{NF}-\kappa \mathrm{B}$ and JNK1/AP-1 pathways, which then activated the transcription of proinflammatory genes. These genes encode proinflammatory molecules, including cytokines, chemokines, and other effectors of the innate immune response, and induce the onset and progression of murine diet-induced nonalcoholic steatohepatitis $(24,25)$. The activation of TLR4-MyD88-dependent signaling also exacerbates liver inflammation through stimulating TNF- $\alpha$ and IL-1 $\beta$. This effect has been demonstrated by the observations that TLR4-deficient mice show decreased expression levels of TNF- $\alpha$ and IL-1 $\beta$ in NAFLD models $(26,27)$. The present study also found that the hepatic expression of TLR4 was decreased following the administration of pioglitazone, which was accompanied with downregulation in the expression levels of MyD88, IKK- $\beta$, NF- $\kappa$ B, JNK1, AP-1, TNF- $\alpha$ and IL- $1 \beta$. Thus, pioglitazone may alleviate MCD-induced liver inflammation and fibrosis through downregulation of the expression levels of TLR4 and its downstream genes.

To further clarify the mechanism by which pioglitazone alleviates MCD-induced liver fibrosis in mice, the hepatic expression levels of BAMBI, TGF- $\beta 1, \alpha-$ SMA and Col-1 were assessed. It has been reported that activated HSCs express TLR4 (28). However, TLR4-signaling modulates the activation of quiescent HSCs and the transformation into myofibroblast-like cells, which secrete extracellular matrix (ECM) and promotes hepatic fibrogenesis in nutritional fibrotic steatohepatitis. TGF- $\beta 1$ is considered to be the most potent mediator of HSC activation (29). Previously, Li et al reported that TLR4 downregulated the expression of the TGF- $\beta 1$ pseudoreceptor, BAMBI, to sensitize HSCs to TGF- $\beta 1$-induced signals (30). In the present study, with the induction of TLR4, the expression levels of hepatic TGF- $\beta 1, \alpha-$ SMA and Col-1 were significantly increased, whereas the expression of BAMBI was markedly decreased in the MCD diet-fed mice, compared with the mice in the control group, indicating HSC activation and collagen deposition. The possible mechanisms underlying the TLR4-mediated HSC activation and hepatic fibrosis in the MCD mice were that TLR4/MyD88 induced the stimulation of $\mathrm{NF}-\kappa \mathrm{B}$, repressed the transcription of BAMBI in HSCs and increased the production of IL-1 $\beta$. In addition, the HSC-derived MCP-1 acted in an autocrine manner to activate the HSCs (31), and MIP-1 $\alpha$ enhanced extensive HSC proliferation $(32,33)$. Activated HSCs secrete excessive ECM to induce liver fibrosis (34). Due to its inflammatory action in, pioglitazone reversed the activation of HSCs and inhibited hepatic nutritional fibrosis in the mice by modulating the expression levels of PPAR $\gamma$ and TLR4, which further upregulated the expression of BAMBI and downregulated the expression levels of TGF- $\beta 1, \alpha-$ SMA and Col-1. This effect may be enhanced by the efficacy of the PPAR $\gamma$ agonist, pioglitazone, by modulation of the hepatic expression levels of lipid metabolism-, oxidative stress- and apoptosis-associated genes. On assessment of the findings, the present study hypothesized that pioglitazone has a protective role in nutritional fibrotic steatohepatitis in mice, which is associated with the targeted activation of PPAR $\gamma$ and modulation of the TLR4-mediated signaling pathway.

In conclusion, the present study provided insight into the importance of TLR4-dependent signaling in the development of 
nutritional fibrotic steatohepatitis. In addition, the PPAR $\gamma$ agonist, pioglitazone exerted its anti-inflammatory and anti-fibrotic effects by modulating the TLR4-dependent signaling pathways of IKK- $\beta / \mathrm{NF}-\kappa \mathrm{B}$ and JNK1/AP-1, and the expression levels of the fibrogenic genes, BAMBI, TGF- $\beta 1, \alpha$-SMA and Col- 1 . These results indicated the potential role, and underlying molecular mechanism, of pioglitazone in the prevention and treatment of nutritional fibrotic steatohepatitis.

\section{Acknowledgements}

The study was supported by the National Natural Science Foundation of China (grant no. 81370536) and the Hebei Provincial Natural Science Fund (grant no. H2013206276).

\section{References}

1. Mitchell PS, Parkin RK, Kroh EM, Fritz BR, Wyman SK, Pogosova-Agadjanyan EL, Peterson A, Noteboom J, O'Briant KC Allen A, et al: Circulating microRNAs as stable blood-based markers for cancer detection. Proc Natl Acad Sci USA 105: 10513-10518, 2008.

2. Cohen JC, Horton JD, and Hobbs HH: Human fatty liver disease: Old questions and new insights. Science 332: 1519-1523, 2011.

3. Kelishadi R and Poursafa P: Obesity and air pollution: Global risk factors for pediatric non-alcoholic fatty liver disease. Hepat Mon 11: 794-802, 2011.

4. Söderberg C, Stål P, Askling J, Glaumann H, Lindberg G, Marmur J and Hultcrantz R: Decreased survival of subjects with elevated liver function tests during a 28-year follow-up. Hepatology 51: 595-602, 2010.

5. Guo J and Friedman SL: Toll like receptor 4 signaling in liver injury and hepatic fibrogenesis. Fibrogenesis Tissue Repair 3: 21, 2010.

6. Fuentes E, Guzmán-Jofre L, Moore-Carrasco R and Palomo I: Role of PPARs in inflammatory processes associated with metabolic syndrome. Mol Med Rep 8: 1611-1616, 2013.

7. Nan YM, Han F, Kong LB, Zhao SX, Wang RQ, Wu WJ and Yu J: Adenovirus-mediated peroxisome proliferator activated receptor gamma overexpression prevents nutritional fibrotic steatohepatitis in mice. Scand J Gastroenterol 46: 358-369, 2011.

8. Nan YM, Fu N, Wu WJ, Liang BL, Wang RQ, Zhao SX, Zhao JM and $\mathrm{Yu}$ J: Rosiglitazone prevents nutritional fibrosis and steatohepatitis in mice. Scand J Gastroenterol 44: 358-365, 2009.

9. Ji Y, Liu J, Wang Z, Liu N and Gou W: PPARgama agonist, rosiglitazone, regulates angiotensin II-induced vascular inflammation through the TLR4-dependent signaling pathway. Lab Invest 89: 887-902, 2009.

10. Leclercq IA, Lebrun VA, Stärkel P and Horsmans YJ: Intrahepatic insulin resistance in a murine model of steatohepatitis: Effect of PPARgamma agonist pioglitazone. Lab Invest 87: 56-65, 2007.

11. Da Silva Morais A, Lebrun VA, Abarca-Quinones J, Brichard S, Hue L, Guigas B, Viollet B and Leclercq IA: Prevention of steatohepatitis by pioglitazone: Implication of adiponectin-dependent inhibition of SREBP-1c and inflammation. J Hepatol 50: 489-500, 2009.

12. Ballestri S, Lonardo A and Loria P: Nonalcoholic fatty liver disease activity score and Brunt's pathologic criteria for the diagnosis of nonalcoholic steatohepatitis: What do they mean and do they agree? Hepatology 53: 2142-2143, 2011.

13. Alkhouri N, De Vito R, Alisi A, Yerian L, Lopez R, Feldstein AE and Nobili V: Development and validation of a new histological score for pediatric non-alcoholic fatty liver disease. J Hepatol 57: 1312-1318, 2012.

14. Livak KJ and Schmittgen TD: Analysis of relative gene expression data using real-time quantitative PCR and the $2^{-\Delta \Delta \mathrm{Ct}}$ method. Methods 25: 402-408, 2001.

15. Estep M, Armistead D, Hossain N, Elarainy H, Goodman Z, Baranova A, Chandhoke V and Younossi ZM: Differential expression of miRNAsliver disease. Aliment Pharmacol Ther 32: 487-497, 2010.
16. Wang RQ, Nan YM, Wu WJ, Kong LB, Han F, Zhao SX, Kong L and $\mathrm{Yu}$ J: Induction of heme oxygenase-1 protects against nutritional fibrosing steatohepatitis in mice. Lipids Health Dis 10: 31, 2011.

17. Berlanga A, Guiu-Jurado E, Porras JA and Auguet T: Molecular pathways in non-alcoholic fatty liver disease. Clin Exp Gastroenterol 7: 221-239, 2014.

18. Hasenfuss SC, Bakiri L, Thomsen MK, Williams EG, Auwerx J and Wagner EF: Regulation of steatohepatitis and PPAR $\gamma$ signaling by distinct AP-1 dimers. Cell Metab 19: 84-95, 2014

19. Xu E, Forest MP, Schwab M, Avramoglu RK, St-Amand E, Caron AZ, Bellmann K, Shum M, Voisin G, Paquet M, et al: Hepatocyte-specific Ptpn6 deletion promotes hepatic lipid accretion, but reduces NAFLD in diet-induced obesity: Potential role of PPAR $\gamma$. Hepatology 59: 1803-1815, 2014.

20. Villalpando-Arteaga EV, Mendieta-Condado E, Esquivel-Solís H, Canales-Aguirre AA, Gálvez-Gastélum FJ, Mateos-Díaz JC, Rodríguez-González JA and Márquez-Aguirre AL: Hibiscus sabdariffa L. aqueous extract attenuates hepatic steatosis through down-regulation of PPAR- $\gamma$ and SREBP-1c in diet-induced obese mice. Food Funct 4: 618-626, 2013.

21. Spruss A, Kanuri G, Wagnerberger S, Haub S, Bischoff SC and Bergheim I: Toll-like receptor 4 is involved in the development of frustose-induced hepatic steatosis in mice. Hepatology 50: 1094-1104, 2009.

22. Wagnerberger S, Spruss A, Kanuri G, Volynets V, Stahl C, Bischoff SC and Bergheim I: Toll-like receptors 1-9 are elevated in livers with fructose-induced hepatic steatosis. Br J Nutr 107: 1727-1738, 2012

23. Shirai Y, Yoshiji H, Noguchi R, Kaji K, Aihara Y, Douhara A, Moriya K, Namisaki T, Kawaratani H and Fukui H: Cross talk between toll-like receptor-4 signaling and angiotensin-II in liver fibrosis development in the rat model of non-alcoholic steatohepatitis. J Gastroenterol Hepatol 28: 723-730, 2013.

24. Guo J and Friedman SL: Toll-like receptor 4 signaling in liver injury and hepatic fibrogenesis. Fibrogenesis Tissue Repair 3: 21-39, 2010.

25. Szabo G, Velayudham A, Romics L Jr and Mandrekar P: Modulation of non-alcoholic steatohepatitis by pattern recognition receptors in mice: The role of toll-like receptors 2 and 4. Alcohol Clin Exp Res 29 (Suppl 11): S140-S145, 2005.

26. Dauphinee SM and Karsan A: Lipopolysaccharide signaling in endothelial cells. Lab Invest 86: 9-22, 2006.

27. Csak T, Velayudham A, Hritz I, Petrasek J, Levin I, Lippai D, Catalano D, Mandrekar P, Dolganiuc A, Kurt-Jones E and Szabo G: Deficiency in myeloid differentiation factor-2 and toll-like receptor 4 expression attenuates nonalcoholic steatohepatitis and fibrosis in mice. Am J Physiol Gastrointest Liver Physiol 300: G433-G441, 2011.

28. Aoyama T, Paik YH and Seki E: Toll-like receptor signaling and liver fibrosis. Gastroenterol Res Pract 2010. pii: 192543, 2010.

29. Baghy K, Iozzo RV and Kovalszky I: Decorin-TGF $\beta$ axis in hepatic fibrosis and cirrhosis. J Histochem Cytochem 60: 262-268, 2012

30. Li YS, Ni SY, Meng Y, Shi XL, Zhao XW, Luo HH and Li X: Angiotensin II facilitates fibrogenic effect of TGF- $\beta 1$ through enhancing the down-regulation of BAMBI caused by LPS: A new pro-fibrotic mechanism of angiotensin II. PLoS One 8: e76289, 2013.

31. Saiman Y, Agarwal R, Hickman DA, Fausther M, El-Shamy A, Dranoff JA, Friedman SL and Bansal MB: CXCL12 induces hepatic stellate cell contraction through a calcium-independent pathway. 305: G375-G382, 2013.

32. Cynis H, Kehlen A, Haegele M, Hoffmann T, Heiser U, Fujii M, Shibazaki Y, Yoneyama H, Schilling S and Demuth HU: Inhibition of glutaminyl cyclases alleviates CCL2-mediated inflammation of non-alcoholic fatty liver disease in mice. Int J Exp Pathol 94: 217-225, 2013.

33. Heinrichs D, Berres ML, Nellen A, Fischer P, Scholten D, Trautwein C, Wasmuth HE and Sahin H: The chemokine CCL3 promotes experimental liver fibrosis in mice. PLoS One 8: e66106, 2013.

34. Gressner AM: Transdifferentiation of hepatic stellate cells (Ito cells) to myofibroblasts: A key event in hepatic fibrogenesis. Kidney Int Suppl 54: S39-S45, 1996. 